\title{
INFLUENCE OF MOTHER's PARENTING STYles ON MeNTAl HeAlth OF Adolescents: InTERPLAy OF GENDER
}

\author{
Sonal Chabra and Indrajeet Dutta
}

There is no way in which parents can evade having a determining effect upon their children's personality, character, and competence. The functions of parenting greatly influence how children develop. Amidst the understanding of the importance of the parent-child relationship, it becomes crucial to decipher whether the parenting styles, especially of mothers, really influence the mental health of adolescents. The present study looked into the parenting styles of urban and rural mothers from the perspective of mental health of adolescents. The data was collected from a randomly selected sample of 100 adolescents from the district of Faridabad in the State of Haryana. Parenting Authority Questionnaire by Burie (1991) and Mental Health Inventory was administered to ascertain the parenting styles of mothers and adolescents' mental health. Descriptive statistics was used to analyse the data. The analysis revealed that 'authoritative parenting style' does contribute towards the mental health of adolescents.

KEYWORDS: Parenting Styles, Mental Health, Gender, Adolescents

\section{BACKGROUND}

Petersen (1988) has very well said that adolescence as a phase of life begins in biology and ends in society. Indeed, adolescence may be defined as the period within the life span when most of a person's biological, cognitive, psychological, and social characteristics are changing from what is typically

\footnotetext{
Sonal Chabra $\longrightarrow$

Assistant Professor, Rawal College of Education, Faridabad, India

Email:sonal.chabra77@gmail.com

Indrajeet Dutta

Assistant Professor, Maulana Azad National Urdu University, Bhopal, India

Email:indraneet@gmail.com
} 
considered child-like to what is considered adult-like (Lerner \& Spanier, 1980). The adolescent faces a remarkable challenge in this period, which requires finetuning to changes in the self (body especially), in the family, and in the peer group. This adolescence becomes a period of excitement and of unrest; of joy and of dilemma; of discovery and of perplexity; and of breaks with the past and yet of links with the future. Adolescence can be, then, a confusing time--for the adolescent experiencing this phase of life; for the parents who are nurturing the adolescent during his or her progression through this period; for other adults charged with enhancing the development of youth during this period of life. Since research consistently indicates that adolescents develop better when they feel close to their parents, it would be a serious loss to all concerned if parents acted as if they were no longer important once their children entered adolescence (Erikson, 1968). Romer (2003) further said that during the years of identity formation, as adolescents complete their education and develop vocational plans, and during the time when many teens face numerous risks that can undermine their future, it could be argued persuasively that positive parent-adolescent relationships and interaction are extremely important.

\section{Parenting Styles}

Like adolescence, parenting is both a biological and a social process (Tobach \& Schneirla, 1968). Parenting is a complex process, involving much more than a mother or father providing food, safety, and succour to an infant or child. Parenting involves bidirectional relationships between members of two (or more) generations; can extend through all or major parts of the respective life spans of these groups; may engage all institutions within a culture (including educational, economic, political, and social ones); and is embedded in the history of a people--as that history occurs within the natural and designed settings within which the group lives (Ford \& Lerner, 1992). The key function of a child's family is to raise the young person in as healthy a manner as possible (e.g., see Bornstein, 1995). The parents' role is to provide the child with a safe, secure, nurturing, loving, and supportive environment, one that allows the offspring to have a happy and healthy youth; this sort of experience allows the youth to develop the knowledge, values, attitudes, and behaviours necessary to become an adult making a productive contribution to self, family, community, and society (Lerner, et al., 1995). What a parent does to fulfil these "duties" of his or her role is termed parenting; in other words, parenting is a term that summarizes behaviour shown by a person--usually, but, of course, not exclusively, the mother or father--to raise a child. Parenting effectively during the teen years, as in any developmental period, requires a thorough understanding of the normative developmental changes the adolescent is going through. 
The classic research of Baumrind (1971) resulted in the identification of three major types of child rearing styles: Authoritative, authoritarian, and permissive. The first style of rearing is marked by parental warmth, the use of rules and reasoning (induction) to promote obedience and keep discipline, non-punitive punishment (e.g., using "time out" or "grounding" instead of physical punishment), and consistency between statements and actions and across time (Baumrind, 1971). Authoritarian parents are not warm, stress rigid adherence to the rules they set (obey--just because we, the parents, are setting the rules), emphasize the power of their role, and use physical punishment for transgressions (Baumrind, 1971). Permissive parents do not show consistency in their use of rules, they may have a "laissez-faire" attitude towards their child's behaviour (i.e., they may either not attend to the child or let him or her do whatever he or she wants), and they may give the child anything he or she requests; their style may be characterized as being either more of a peer or, instead, as an independent "observer" of their child. Indeed, because of the diversity of behavioural patterns that can characterize the permissive parenting style. Research makes it clear that the behavioural variation summarized by the use of different categories is associated with differences in adolescent behaviour and development (Lamborn, et al., 1991). For example, in a study of over 4,000 14 to 18 year olds, adolescents with authoritative parents had more social competence and fewer psychological and behavioural problems than youth with authoritarian, indulgent, or neglectful parents (Lamborn, et al., 1991). In fact, youth with neglectful parents were the least socially competent and had the most psychological and behavioural problems of any group of adolescents in the study. In turn, youth with authoritarian parents were obedient and conformed well to authority, but had poorer self concepts than other adolescents. Finally, while youth with indulgent parents had high self confidence, they more often abused substances, misbehaved in school, and were less engaged in school.

There are a range of behaviours and associated emotions exchanged between parents and their adolescent offspring. Some of these exchanges involve positive and healthy behaviours and others involve the opposite; some of the outcomes for adolescent development of these exchanges reflect good adjustment and individual and social success, whereas other outcomes reflect poor adjustment and problems of development. As is true for all facets of human development, there is then diversity in the nature and implications of parent-child relations in adolescence. Whatever style parents use to rear their adolescents, the goal of parenting is to raise a child who is healthy and successful in life, who can contribute to self and to society, who accepts and works to further the social order. In essence, parenting and socialization endures towards individuals with sound mental health. 


\section{Mental Health Of Adolescents}

Although mood swings are common during adolescence, approximately one in five adolescents has a diagnosable mental disorder, such as depression and/or "acting out" conditions that can include extremely defiant behaviour. Mental and behavioural problems are increasing part of the health problems the world over. Indian Council of Medical Research reported that about 12.8 per cent of children (1-16 years) suffer from mental health problems in India. WHO defines mental health as a condition, subject to fluctuations due to biological and social factors, which enables the individual to achieve a satisfactory synthesis of his own potentially conflicting and instinctive drives; to form and maintain harmonious relations with others; and to participate in constructive changes in his social and physical environment." Mental health includes our emotional, psychological, and social well being. It affects how we think, feel and act as we cope with life. It also helps determine how we handle stress, relate to others, and make choices. In this positive sense, mental health is the foundation for well being and effective functioning for an individual and for a community. It is more than the absence of mental illness. Neither mental nor physical health can exist alone but are interdependent. Furthermore, health and illness may co-exist. Important mental health habits-including coping, resilience and good judgment-help adolescents to achieve overall well being and set the stage for positive mental health in adulthood. Mental health is important at every stage of life, from childhood and adolescence through adulthood.

Mental health of adolescents is affected by individual factors and experiences, social interactions, societal structures and cultural values. It is influenced by experiences in everyday life, in families and schools, on streets, and at work. Mental health problems can develop at any point in life and may be influenced by a variety of factors, including genetics or family history of a disorder, chemical imbalances in the brain, or stressors in the environment. Adolescence is a time of great change and transition, when youth are starting to make decisions about career paths, further schooling, and living on their own. These stressors, coupled with changing peer and family interactions, may lead in some cases to mental health problems, such as depression, suicidal thoughts, and anxiety disorders, particularly if the adolescent has a family history of mental illness. Children at every stage particularly adolescence are greatly influenced by their parents' rearing styles. This influence is generally expected to be more of mothers in Indian context because they are expected to spend more time with their adolescents.

\section{REVIEW OF LITERATURE}

Generally, authoritarian and permissive parenting is associated with mental 
health problems in adolescents (Baumrind, 1991), whereas authoritative parenting is associated with their improved mental health and well being (Lamborn, et.al. 1991). Tozandehjani, Tavakolizadeh and Lagzian (2011) did a research on 'The Effect of Parenting Styles on Self-efficacy and Mental Health of Students'. This descriptive-analytical research was done on 210 students (105 males and 105 females) among 3757 humanity students of Payam-e-Noor and Azad Universities in Neyshabour who were selected by multilayer cluster sampling method. The subjects were tested using the child rearing self-efficacy and GHQ-28 questionnaires. The data were analysed using one-way ANOVA, two-factor (F), and Tukey's test. The results indicated that parenting styles had a significant influence on self-efficacy of students $(p=0.0064)$. There was a significant effect on increasing self-efficacy in authoritative style compared with permissive style $(p=0.0001)$ and the authoritarian style $(p=0.01)$. Also, parenting styles had a significant effect on mental health condition $(p=0.027)$. Parenting styles had different significant effects on mental health of students. Authoritative style had an effect more than that of the permissive style. They concluded that the effect of parenting styles on self-efficacy and mental health is of great importance in students and recommended teaching programs about parenting styles for parents at different levels.

Dwairy and Achoui (2006) did their work on 'Parenting styles, individuation and mental health of Arab adolescents: Third Cross-Regional Research Study'. Their study revealed that the Psychological State Scale, Multigenerational Scale, and the Parental Authority Questionnaire were administered to 2,893 Arab adolescents in eight Arab societies. In these tests, adolescents raised according to the inconsistent parenting scored lower in connectedness and higher in mental disorders than those raised according to the controlling or flexible-oriented parenting pattern. Authoritative parenting was associated with a higher level of connectedness with the family and better mental health of adolescents. A higher level of adolescent-family connectedness is associated with better mental health of adolescents. Results indicate that authoritarian parenting within an authoritarian culture does not harm the adolescents' mental health as it does within the Western liberal societies. These results give rise to the hypothesis that inconsistency in parenting and inconsistency between the parenting style and the culture can cause harm to adolescents' mental health.

Usha and Lakshmi (2008) in their work on the Influence of parenting style and self-compassion on mental health of secondary school pupils report that the effect of parenting style on mental health was found to be significant at 0.01 level of significance for the total sample $(f=13.390)$ and the sub samples based on sex (for boys, $\mathrm{f}=5.012$ and for girls $\mathrm{f}=4.991$ ) and locale (for urban, $\mathrm{f}=7.420$ and for rural $f=4.120$ ) at 0.01 level of significance. The effect of parenting style on mental health was found to be significant for aided school pupils $(f=10.761)$ 
at 0.01 level but it was found not to be significant for government school pupils $(f=0.542)$ even at 0.05 level of significance. The effect of self-compassion on mental health was found to be significant for the total sample $(f=12.084)$ and the sub samples based on sex, (for boys, $\mathrm{f}=15.167$ and for girls, $\mathrm{f}=7.691)$, locale (for urban, $\mathrm{f}=11.448$ and for rural, $\mathrm{f}=6.161$ ) and type of school management (for aided, $\mathrm{f}=9.626$ and for government, $\mathrm{f}=14.835$ ) at 0.01 level of significance. The interaction effect of parenting style and self-compassion on Mental health was found not to be significant for total sample $(f=0.851)$ and sub samples based on sex (for boys, $\mathrm{f}=0.375$ and for girls, $\mathrm{f}=0.175$ ), locale (for urban, $\mathrm{f}=$ 1.558 and for rural, $\mathrm{f}=0.727$ ) and type of school management (for aided, $\mathrm{f}=$ 0.689 and for government, $\mathrm{f}=0.849$ ) even at 0.05 level of significance.

Niaraki and Rezai (2010) studied the 'Self- Esteem, Mental Health and Quality of Life in relation to Parenting Styles of High School Students in Iran'. It was found that there was a significant impact of parenting style on three dimensions of mental health, namely: (a) physical, (b) anxiety, and (c) depression. This means that children raised by authoritative parenting style had better total mental health, better physical mental health and lower anxiety and depression than children raised by authoritarian and permissive parenting styles. However, it was found that parenting style did not impact social mental health.

\section{OBJeCTIVES Of THE STUDY}

Amidst the understanding of the importance of the parent-child relationship, it becomes crucial to decipher whether the parenting styles really influence the mental health of adolescents. The objectives of the study were:

1. To study the parenting styles of mothers of adolescents.

2. To study the difference in parenting styles among mothers of adolescents on the basis of their gender.

3. To study the mental health of adolescents.

4. To study the difference in mental health among adolescents on the basis of their gender.

5. To study the influence of parenting styles on mental health of adolescents.

\section{HYPOTHESIS}

1. There is no difference in parenting styles among mothers of adolescents on the basis of their gender.

2. There is no difference in mental health among adolescents on the basis of their gender. 
3. There is no influence of parenting styles on mental health of adolescents.

\section{METHODOLOGY}

The study employed a descriptive survey method. The details are given as under:

\section{SAMPLE}

The sample comprised of 100 ( 50 boys and 50 girls) adolescents from the district of Faridabad. Five schools were selected from the district of Faridabad by convenient sampling method. Further from each school 20 adolescents were identified based on random sampling. Among these adolescents there were an equal number of boys and girls. The adolescents were chosen from classes IX and X.

\section{TOOLS USED}

The tools used for collecting the data were:

\section{Parental Authority Questionnaire}

The PAQ was designed by Buri based on the Baumurind's research on the parenting style in the year 1991 to find out the particular parenting topology being exhibited by the parents towards their child. This questionnaire is to be filled by the child. It is 30-item questionnaire and contains 10 items each on permissive, authoritative and authoritarian parenting style. It is a five point likert scale ranging from strongly disagree to strongly agree. The maximum score for each parenting topology is 50 whereas minimum score is 10 . The higher score of a particular type of parenting typology indicates the parenting style of the parent of that child. The questionnaire has very high reliability as being tested through testretest method ( 0.81 for permissiveness, 0.86 for authoritarian and 0.78 for authoritative in case of mother). The internal consistency of items is being measured by Cronbach alpha (0.75 for permissiveness, 0.85 for authoritarian and 0.82 for authoritative in case of mother). This Questionnaire has high discriminant validity as well as high criterion validity.

\section{Mental Health Inventory (MHI-38)}

The inventory has 38 items scored on a six-point scale (range 1-6) except two items 9 and 28 which are scored on a five-point scale (range 1-5). The MHI may be aggregated into: (i) Six subscales - Anxiety, Depression, Loss of Behavioural / Emotional Control, General Positive Affect, Emotional Ties and Life Satisfaction; (ii) Two global scales - Psychological Distress and 
Psychological Well-being; and (iii) A global Mental Health Index score. Scoring of MHI is relatively complicated by the fact that items making up the various subscales and global scales may be recoded (or reversed scored) differently depending on the underlying construct being measured.

\section{DATA ANALYSIS}

The data collected through parenting styles and mental health inventory was analysed through inferential statistics. To identify the parenting style of adolescents' manual of PAQ was used whereas to find the mental health of adolescents a manual of MHI was referred. To compare the parenting styles and mental health of adolescents the t-test was used and to study the influence of parenting styles on mental health regression analysis was done.

\section{REsults Of The STUdY}

The data was analysed in the light of hypothesis designed for the study and findings have been encapsulated in the following headings for better comprehensibility of the readers.

\section{PARENTING STYLes OF MOTHERS}

With regard to perception of adolescents regarding parenting styles, $38 \%$ felt that their parents had authoritative parenting style; another $31 \%$ believed that their parents had permissive style and 22\% said that their parents had authoritarian parenting style. While $9 \%$ adolescents did not have a clear perception of their parents parenting styles, they got equal scores on at least two of the parenting styles.

\section{Difference In Parenting Styles Of Mothers Based On Gender Of AdOLESCENTS}

Table 1 indicates that higher percentage (19\%) of female children had reported that their parents had permissive parenting style, whereas $25 \%$ of the male students felt that their parents had authoritative parenting style. 


\section{Table 1}

Parenting Style of Mothers of Male and Female Adolescents.

\begin{tabular}{|l|l|c|c|c|}
\hline S.No & Gender & Permissive & Authoritative & Authoritarian \\
\hline $\mathbf{1}$ & Male & $12 \%$ & $25 \%$ & $9 \%$ \\
\hline $\mathbf{2}$ & Female & $19 \%$ & $13 \%$ & $13 \%$ \\
\hline $\mathbf{3}$ & Total & $31 \%$ & $38 \%$ & $22 \%$ \\
\hline
\end{tabular}

The objective was to further decipher whether the parenting style of mothers on three parenting topologies as reported by the male and female adolescents differed. For the same, $t$ value was calculated and it was found out that only in the case of authoritative parenting style the calculated $t$ value (3.15) is higher than the table value at $\mathrm{df}=98$ which was significant at 0.01 level (see Table 2). This indicates that there is significant difference in authoritative parenting styles of mothers on the basis of their gender. In case of permissive and authoritarian both the groups did not differ significantly.

Table 2

Comparison of Parenting Styles of Mothers on Gender Basis.

\begin{tabular}{|c|c|c|c|c|c|}
\hline S.No & Variable & $\mathbf{N}$ & Mean & SD & $t$ \\
\hline \multirow[t]{2}{*}{1} & \multirow[t]{2}{*}{ Permissive } & 50 & 25.70 & 3.28 & \multirow[t]{2}{*}{0.67} \\
\hline & & 50 & 26.14 & 3.21 & \\
\hline \multirow[t]{2}{*}{2} & \multirow[t]{2}{*}{ Authoritative } & 50 & 27.42 & 3.86 & \multirow[t]{2}{*}{$3.15^{*}$} \\
\hline & & 50 & 25.16 & 3.27 & \\
\hline \multirow[t]{2}{*}{3} & \multirow[t]{2}{*}{ Authoritarian } & 50 & 25.26 & 3.67 & \multirow{2}{*}{0.20} \\
\hline & & 50 & 25.40 & 2.98 & \\
\hline
\end{tabular}

\section{( ${ }^{*}$ Significant at 0.01 level)}

Thus, it can be concluded that in case of authoritative parenting style gender is the factor of differentiation and boys perceive their parents as authoritative. This has to be understood in the context that parents are generally expected to be more lenient with their boys when it comes to Indian settings.

\section{Mental Health Of Adolescents}

For understanding the mental health of adolescents the mean total score of subscales, global scales and overall MHI was calculated and it has been presented in Table 3. 
Table 3

Mean Scores of Adolescents on Various Components of MHI.

\begin{tabular}{|c|l|l|c|c|}
\hline S.No & Type of Scales & Components of Scales & $\begin{array}{c}\text { Mean } \\
\text { Scores }\end{array}$ & Inference \\
\hline 1 & \multirow{2}{*}{ Subscales } & Anxiety & 28.57 & Average \\
\cline { 3 - 5 } & & Depression & 12.24 & Average \\
\cline { 3 - 5 } & & $\begin{array}{l}\text { Loss of Behavioural / } \\
\text { Emotional Control }\end{array}$ & 26.93 & Average \\
\cline { 3 - 5 } & & General Positive Affect & 30.48 & Average \\
\cline { 3 - 5 } & & Emotional Ties & 6.47 & Average \\
\cline { 3 - 5 } & & Life Satisfaction & 2.78 & Average \\
\hline 2 & \multirow{2}{*}{ Global Scales } & Psychological Distress & 73.45 & Low \\
\cline { 3 - 6 } & & $\begin{array}{l}\text { Psychological Well } \\
\text { being }\end{array}$ & 43.04 & Average \\
\hline 3 & $\begin{array}{l}\text { Mental Health } \\
\text { Index }\end{array}$ & - & 137.11 & Average \\
\hline
\end{tabular}

In the Mental Health Inventory, the subscales- anxiety, depression and loss of behavioural/ emotional control contributes towards the negative mental health whereas general positive effect, emotional ties and life satisfaction contributes towards positive mental health. The mean score of adolescent in both the cases lies in the average scale as per the range given in the manual and reproduced in Table 5. Therefore, the researchers can safely conclude that adolescents have average mental health. In case of Global Scales which consists of two sub scales- psychological distress and psychological well-being, the mean score obtained in case of psychological distress was 73.45 which is low as per the manual and thus indicates towards positive mental health. The mean score obtained in case of psychological well being was 43.04 which supports the value obtained for low psychological distress. The overall mental health of adolescents was calculated and the mean score obtained was 137.11 which indicates an average mental health.

\section{Comparison Of Mental Health Among Adolescents On The BASIS OF GENDER}

The mean and standard deviation of mental health scores were calculated on the basis of gender. To compare the male and female adolescents on various subscales t-test was applied which is presented in Table 4. From the table it is evident that in none of the six subscales i.e. anxiety, depression, emotional control, general positive effect, emotional ties and life satisfaction there is a significant difference between the two groups. Thus, we can say that gender did not act as one of the variable of differentiation on MHI. 
244| Sonal Chabra and Indrajeet Dutta

Table 4

Comparison on Subscales of Mental Health Based on Gender.

\begin{tabular}{|c|c|c|c|c|c|}
\hline S.No & Variable & $\mathbf{N}$ & Mean & SD & $t$ \\
\hline \multirow[t]{2}{*}{1} & \multirow[t]{2}{*}{ Anxiety } & 50 & 29.08 & 5.67 & \multirow[t]{2}{*}{1.01} \\
\hline & & 50 & 28.06 & 4.32 & \\
\hline \multirow[t]{2}{*}{2} & \multirow[t]{2}{*}{ Depression } & 50 & 12.46 & 2.90 & \multirow[t]{2}{*}{0.75} \\
\hline & & 50 & 12.02 & 2.95 & \\
\hline \multirow[t]{2}{*}{3} & \multirow{2}{*}{$\begin{array}{l}\text { Loss of Behavioural / } \\
\text { Emotional Control }\end{array}$} & 50 & 27.56 & 4.47 & \multirow[t]{2}{*}{1.41} \\
\hline & & 50 & 26.30 & 4.40 & \\
\hline \multirow[t]{2}{*}{4} & \multirow[t]{2}{*}{ General Positive Affect } & 50 & 30.92 & 4.04 & \multirow[t]{2}{*}{1.06} \\
\hline & & 50 & 30.04 & 4.23 & \\
\hline \multirow[t]{2}{*}{5} & \multirow[t]{2}{*}{ Emotional Ties } & 50 & 6.48 & 2.14 & \multirow[t]{2}{*}{0.04} \\
\hline & & 50 & 6.46 & 2.17 & \\
\hline \multirow[t]{2}{*}{6} & \multirow[t]{2}{*}{ Life Satisfaction } & 50 & 2.92 & 1.20 & \multirow[t]{2}{*}{1.15} \\
\hline & & 50 & 2.64 & 1.22 & \\
\hline
\end{tabular}

Further, MHI can also be calculated in terms of two global subscales i.e. Psychological Distress and Psychological Well-being. The mean and standard deviation of scores on global scales were calculated on the basis of gender also. To compare adolescents on the basis of gender on the global subscales, t-test was applied which is presented in the Table 5. It is evident from Table 5 that the $t$ value for Psychological Distress is 1.63 at $\mathrm{df}=98$ which is higher than table value at 0.05 level of significance, therefore, there is a significant difference between the male and female adolescents whereas in case of Psychological well-being calculated $t$ value is lower than the table value which indicates there was no significant difference between the two groups.

\section{Table 5}

Comparison on Global Scales of Mental Health Based on Gender.

\begin{tabular}{|c|c|c|c|c|c|}
\hline S.No & Variable & $\mathbf{N}$ & Mean & S.D & $t$ \\
\hline \multirow[t]{2}{*}{1} & \multirow[t]{2}{*}{ Psychological Distress } & 50 & 74.92 & 9.46 & \multirow{2}{*}{$1.63^{*}$} \\
\hline & & 50 & 71.98 & 8.49 & \\
\hline \multirow[t]{2}{*}{2} & \multirow[t]{2}{*}{ Psychological Well being } & 50 & 43.54 & 5.97 & \multirow{2}{*}{0.87} \\
\hline & & 50 & 42.54 & 5.45 & \\
\hline
\end{tabular}

( ${ }^{*}$ Significantat 0.05 level)

Another way of analysis given by $\mathrm{MH}$ inventory is overall $\mathrm{MHI}$ score. The mean of overall MHI was calculated for male and female adolescents and it was found out that there was no significant difference in the mean scores of male and female adolescents as reflected in Table 6. 
Table 6

Comparison on Overall Mental Health Based on Gender.

\begin{tabular}{|c|l|c|c|c|c|}
\hline S.No & Variable & $\mathbf{N}$ & Mean & S.D & $\boldsymbol{t}$ \\
\hline \multirow{2}{*}{1} & Mental Health Index & 50 & 136.75 & 10.52 & \multirow{2}{*}{0.42} \\
\cline { 3 - 6 } & & 50 & 137.56 & 8.57 & \\
\hline
\end{tabular}

\section{Influence OF PaRenting STYles On Mental Health}

For studying the influence of parenting style on mental health, regression analysis was carried out where all the three topologies of parenting style i.e. permissive authoritative and authoritarian were acting as predictor variables or independent variables and mental health was dependent variable as given in Table 7 and 8.

\section{Table 7}

Mean and SD Scores Obtained by Adolescents in Mental Health Inventory and Parenting Style Scale.

\begin{tabular}{|l|c|c|c|}
\hline \multicolumn{1}{|c|}{ Variable } & Mean & $\begin{array}{c}\text { Standard } \\
\text { Deviation }\end{array}$ & N \\
\hline Mental Health & 137.11 & 9.52 & 100 \\
\hline Permissive & 25.92 & 3.24 & 100 \\
\hline Authoritative & 26.29 & 3.74 & 100 \\
\hline Authoritarian & 25.33 & 3.33 & 100 \\
\hline
\end{tabular}

Table 8 shows the multiple linear regression model summary and overall fit statistics. We find that the adjusted $\mathrm{R}^{2}$ of our model is -0.009 with the $\mathrm{R}^{2}=$ 0.022. This means that the linear regression model with the independent variables i.e. permissive, authoritative and authoritarian explains $2.2 \%$ of the variance of the mental health.

Table 8

Pearson Coefficient of Mental Health and Dimensions of Parenting Style.

\begin{tabular}{|c|c|c|c|}
\hline $\mathrm{R}$ & R Square & $\begin{array}{c}\text { Adjusted R } \\
\text { Square }\end{array}$ & $\begin{array}{c}\text { Std. Error of the } \\
\text { Estimate }\end{array}$ \\
\hline $0.147(\mathrm{a})$ & 0.022 & -0.009 & 9.56 \\
\hline
\end{tabular}

(a Predictors: (Constant), AUTH, AUT, PER)

Table 9 gives the results of the F-test, or ANOVA. The F-Test is the test of significance of the multiple linear regressions. The F-test has the null 
hypothesis that there is no linear relationship between the variables (in other words $\mathrm{R}^{2}=0$ ). The F-test is not significant, thus we can assume that there is a no linear relationship between the variables in our model.

Table 9

Analysis of Variance (ANOVA) between Mental Health and Dimensions of Parenting Style.

\begin{tabular}{|c|l|c|c|c|c|c|}
\hline \multirow{2}{*}{ Model } & & $\begin{array}{c}\text { Sum of } \\
\text { Squares }\end{array}$ & Df & $\begin{array}{c}\text { Mean } \\
\text { Square }\end{array}$ & F & Sig. \\
\hline \multirow{2}{*}{1} & Regression & 194.22 & 3 & 64.74 & 0.70 & $0.55(\mathrm{a})$ \\
\cline { 2 - 8 } & Residual & 8785.56 & 96 & 91.51 & & \\
\cline { 2 - 8 } & Total & 8979.79 & 99 & & & \\
\hline
\end{tabular}

a Predictors: (Constant), AUTH, AUT, PER, b Dependent Variable: MHI

Since we have multiple independent variables in the analysis the Beta weights compare the relative importance of each independent variable in standardized terms. We find that authoritative parenting style had a higher impact than other two parenting styles, beta (authoritative) $=0.12$ and beta (permissive $)=0.05$ and beta $($ authoritarian $)=0.07$ as given in Table 10 .

Table 10

Regression Analysis of Various Dimensions of Parenting Style.

\begin{tabular}{|l|c|c|c|c|c|c|c|}
\hline \multirow{2}{*}{ Model } & \multicolumn{2}{|c|}{$\begin{array}{c}\text { Unstandardized } \\
\text { Coefficients }\end{array}$} & $\begin{array}{c}\text { Standardized } \\
\text { Coefficients }\end{array}$ & $t$ & \multicolumn{2}{|c|}{ Sig. } & \multicolumn{2}{c|}{$\begin{array}{c}\text { 95\% Confidence } \\
\text { Interval for B }\end{array}$} \\
\cline { 2 - 8 } & B & $\begin{array}{c}\text { Std. } \\
\text { Error }\end{array}$ & Beta & & & $\begin{array}{c}\text { Lower } \\
\text { Bound }\end{array}$ & $\begin{array}{c}\text { Upper } \\
\text { Bound }\end{array}$ \\
\hline 1(Constant) & 146.45 & 12.61 & & 11.60 & .000 & 121.41 & 171.50 \\
\hline PER & 0.14 & 0.30 & 0.05 & 0.49 & 0.62 & -0.44 & 0.74 \\
\hline AUT & -0.30 & 0.25 & -0.12 & -1.18 & 0.23 & -0.81 & 0.20 \\
\hline AUTH & -0.20 & 0.29 & -0.07 & -0.69 & 0.48 & -0.78 & 0.37 \\
\hline
\end{tabular}

Thus we can conclude that though there is no significant difference among the parenting style as perceived by adolescents but authoritative parenting styles does contribute towards the mental health of adolescent. Karavasilis, Doyle, and Markiewicz (2003), found positive association between authoritative parenting styles and secure attachment style. Other research findings also demonstrate that an authoritative parenting style produces a number of positive developmental outcomes in adolescents.

\section{CONCLUSION}

Parents are charged with an awesome responsibility by society. Society 
expects parents to do a good job, to create healthy and productive citizens. This study was aimed to explore the influence of parenting styles of mothers on mental health of adolescents. The analysis revealed that authoritative parenting style does contribute towards the mental health of adolescents. Developmental psychologists overwhelmingly endorse authoritative parenting as the optimal parenting style for raising adolescents (Steinberg, 2001). An authoritative parenting style that includes parental monitoring and supervision promotes adolescents exposure to positive activities and reduces the opportunities for engaging in delinquent and risky behaviour (Wargo, 2007). The findings of the present study provides some insights to parents, psychologists and researchers in promoting adolescents' psychosocial development, mental health and general well being. It is also suggested that future research studies be conducted considering parents' age, educational level, socio-economic status, family size, and parental background etc. to study the relationship of parenting styles and attachment styles of adolescents.

\section{REFERENCES}

Baumrind, D. (1971). Current patterns of parental authority. Developmental Psychology Monographs, 4(1), Part 2.

Baumrind, D. (1978). Parental disciplinary patterns and social competence in children. Youth \& Society, 9(3), 239-251.

Bornstein, M.H. (Ed.), (1995). Handbook of parenting, Vol. 3: Status and social conditions of parenting. Mahwah, NJ: Lawrence Erlbaum Associates, Inc.

Dwairy, M., \& Achoui, A. (2006). Parenting styles, individuation and mental health of Arab adolescents: Third Cross-Regional Research Study. Journal of Cross-Cultural Psychology, 37, 221-225.

Erikson, E. H. (1968). Identity: Youth and crisis. New York, NY: Norton.

Ford, D. L., \& Lerner, R. M. (1992). Developmental systems theory: An integrative approach. Newbury Park, CA:Sage.

Karavasilis, L., Doyle, A. B., \& Markiewicz. (2003). Associations Between Parenting Style and Attachment to Mother in Middle Childhood and Adolescence. International Journal of Behavioural Development, 27, 153164.

Lamborn, S. D., Mants, N. S., Steinberg, L., \& Dornbusch, S. M. (1991). Patterns of competence and adjustment among adolescents from authoritative, authoritarian, indulgent, and neglectful families. Child Development, 62, 1049-1065.

Lerner, R. M., \& Spanier, G. B. (1980). A dynamic interactional view of child and family development. In R. M. Lerner \& G. B. Spanier (Eds.), Child Influences on Marital and Family Interaction: A Life-Span Perspective (120). New York: Academic. 
Lerner, R. M., Castellino, D. R., Terry, P. A., Villarruel, F. A., \& McKinney, M. H. (1995). A developmental contextual perspective on parenting. In M. H.Bornstein (Ed.), Handbook of parenting: Biology and ecology of parenting, 2, 285-309. Hillsdale, NJ: Erlbaum.

Niaraki., \& Rezai, F. (2010) Self-Esteem, Mental Health and Quality of Life in relation to Parenting Styles of High School Students in Iran, Unpublished Doctoral Dissertation, Jamia Milia Islamia, Delhi.

Petersen, A. C. (1988). Adolescent development, Annual Review of Psychology, 39, 583-607.

Romer, D. (2003). Reducing adolescent risk: Toward an integrated approach. Thousand Oaks, CA: Sage Publications.

Steinberg, L. (2001). We know some things: Adolescent-parent relationships in retrospect and prospect. Journal of Research on Adolescence, 11, 1-19.

Tozandehjani, H., Tavakolizadeh, J., \& Lagzian, Z. (2011). The Effect of Parenting Styles on Self-efficacy and Mental Health of Students, The Horizon of Medical Sciences, 17(2), 56-64.

Tobach, E., \& Schneira, T. C. (1968). The biopsychology of social behavior of animals. In R.E. Cooke \& S. Levin (Eds.), Biologic basis of paediatric practice (pp. 68-82). New York: McGraw-Hill.

Usha, P., \& Lakshmi, S. (2008). Influence of Parenting Style and Self Compassion on Mental Health of School Pupils. Journal of All India Association for Educational Research, 20(1\&2), 99-102.

Wargo, E. (2007, September). Adolescents and risk: Helping young people make better choices. ACT for Youth Center of Excellence: Research Facts and Findings. Retrieved from http://www.actforyouth.net /documents/Adolescent Risk_Sept07.pdf. 